\title{
Use of Packer Test Results in Hydrogeological Characterization: A Comparison of Calculation Methods for a Representative Value
}

\author{
Fethangest Weldemariyam Tesema ${ }^{1 *}$ and Mehmet Ekmekci ${ }^{2}$ \\ ${ }^{1}$ Department of Geology, School of Earth Sciences, P.O. Box 3066, Mekelle University \\ Main Campus, Mekelle, Ethiopia (*Fethangest17@gmail.com). \\ ${ }^{2}$ Hydrogeological Engineering program, Hacettepe University, Beytepe, Ankara, Turkey.
}

\begin{abstract}
Packer test is one of the commonly applied methods in determination of hydraulic conductivity particularly in low permeability fractured rock mass. Originally, hydraulic conductivity is defined in Lugeon units which correspond to 1 litre per minute per meter of intake section less than 10 atmospheres of pressure. Since the test is applied under different pressures, which gives the opportunity to observe the hydraulic behaviour of the rock under different stresses. Calculations of hydraulic conductivity for each step of pressure usually give different value of hydraulic conductivity. Selection of a representative hydraulic conductivity value therefore becomes an issue. The arithmetic mean is the commonly accepted value, without justifying its representativeness. In this paper, about 75 packer tests conducted at 17 core wells at different depth with $3.5 \mathrm{~m}$ long test sections using double packer were evaluated. The tests are conducted at five pressures that run in three increasing and two decreasing pressures according to the recommendation of Houlsby. Hydraulic conductivity was calculated for every pressure step and evaluated to find a representative value using different methods. The representative values found by different methods is then compared. Results indicate that the arithmetic mean has good correlation with all the methods in particular it is nicely correlated with the modified Lugeon analysis for hydrogeological investigations with a correlation value of $\mathrm{R}^{2}=0.91$. Therefore, it is concluded that the uncertainty associated with the use of the simple arithmetic mean is within an acceptable range of error.
\end{abstract}

Keywords: Hydrogeology, Lugeon Value, Packer test, Permeability.

\section{INTRODUCTION}

Packer tests are one of the hydraulic test methods conducted in the field to obtain the hydraulic property of a rock mass. Packer testing is used to determine the hydraulic conductivity of fractured rock mass. The test is performed in a borehole with water injected into a test section which is isolated from the rest of the borehole with a single packer or two inflated packers. The tests are performed by measuring the flow rate of water injected into the isolated test section of the borehole at a given pressured head. Calculations are based on Darcy's law which assumes laminar flow. The hydraulic conductivity is given in terms of Lugeon value, which is empirically defined as the hydraulic conductivity required to achieve a flow rate of 1 liter per minute per meter of test interval under a reference water pressure equal to 10bar (Quiñones-Roza, 2010). Depending on the application, the test interval can 
vary from tens of centimetres to ten of meters in length. Packer can be used to isolate an individual fracture, a group of fractures, or an entire rock formation. In some test programs, fixed test intervals may vary in length, and the borehole is tested in consecutive sections throughout its length to obtain a hydraulic conductivity profile. Other test programs concentrate on testing only the more permeable portions of the borehole. In such cases, the test intervals may vary in length, depending on borehole conditions as inferred from geophysical logs and core logs.

In a packer test, water is injected under pressure at a constant hydraulic head in an isolated portion of the boreholes measuring the flow rate at a steady state condition. In the process of the packer test development starting from the standard Lugeon (1933) which specifies the use of single pressure in a given test section and modified by Houlsby (1976); and Houlsby (1990) to use a range of pressures rather than a single pressure. Houlsby (1976), in his work, has indicated how to select the representative Lugeon value from the range of pressure tests conducted in a given section based on Lugeon patterns for his geotechnical purposes. However, Roeper et al. (1992) has made little modification in the representative Lugeon selection based on their objective to implement the method for hydrogeological investigation.

Although, the above methods suggest how to select the representative Lugeon value based on the patterns observed and relating the patterns to the flowing nature and geology of the test section in practical applications there is a tendency of using different mean values to find the representative values. The mean values that are in use are arithmetic mean, geometric mean and harmonic mean. However, according to Quiñones-Roza (2010) selecting a representative value from the varying hydraulic conductivity measured using averages is not enough to decide.

Therefore, the objective of this work is to see if the different mean value method of selecting representative Lugeon value can be correlated with specified method of Houlsby (1976); and Houlsby (1990); and Roeper et al. (1992) within the acceptable range of error.

\section{BASIC PRINCIPLE OF PACKER TEST}

It is important to understand the mathematical background and assumptions used to find the hydraulic conductivity based on the packer test. The packer tests, like the other hydraulic tests, follow basic flow principle and is based on the following assumption that the test section assumed to satisfy. These assumptions are test section is isotropic, homogenous, 
radial flow, steady state flow and flow is laminar. According to the NRC (1996), the assumption of isotropy is made for a practical reasons and homogeneity is assumed because the test response in a single borehole is insensitive to changes in hydraulic properties far from the test interval. Since the flow is assumed to follow linear flow by UNESCO (1984); and Klassen (1987) then it can be described by Darcy's law.

Darcy's formula is given by:

$$
Q=K A i
$$

Where, Q: flow rate $\left(\mathrm{L}^{3} / \mathrm{T}\right)$; $\mathrm{K}$ : is the hydraulic conductivity $(\mathrm{L} / \mathrm{T})$;

A: cross-sectional area $\left(\mathrm{L}^{2}\right)$; i: hydraulic gradient (dimensionless)

The above Darcy's formula can be described by the Thiem (1906) equation given the following assumption that is all flow is radial, horizontal, confined, mathematically infinite homogenous aquifer. The Thiem equation was originally developed for pumping tests in a confined porous aquifer media. Where two observation wells are used Wenzel (1936), but it is commonly used in the single well context for packer test in fractured rock Gale (1982); and Novakowski et al. (1997).

As described in the UNESCO (1984) for fractures parallel to the axis of a borehole the injected flow rate is very high compared to the inclined fractures, in this case, there is a need for a special analysis. However, the flow pattern around the test zone depends on the orientation of the fractures in relation to the borehole axis. According to UNESCO (1984) the horizontal fractures (perpendicular to the borehole) or even inclined fissures, the analysis of the test is possible by introducing the approach of cylindrical flow since near the borehole the flow is approximately radial and planar. The simplified formula to the cylindrical flow would, therefore, be valid.

Considering the cylindrical cross-section and the change in head at different distance points of the borehole the Darcy's formula becomes UNESCO (1984):

$$
Q=K 2 \pi r L \frac{d h}{d r}
$$

Where, dh: change in head: $r$ : is the radius of the well: dr: change in distance between points The final formula is: $\quad K=\frac{Q}{2 \pi L \Delta H} \ln R / r$

Here, $\Delta \mathrm{H}$ represents the excessive pressure head measured at the surface from the measuring gage. By definition, the excessive pressure head is the summation of the injection pressure head, the height of the manometer, the depth of the piezometer level or to the centre of test section if the water table is lower than the test section minus the friction losses in 
pipes, connection and packers. The result of the packer test can be described in Lugeon units instead of the absolute result of the hydraulic conductivity and/or permeability. However, the final result is to find the hydraulic conductivity of the rock mass (the test section) under consideration. For this, we need to relate the relative Lugeon units with the absolute hydraulic conductivity measurement. To find the relation among the two measurements see the following calculations (from eq.3).

$$
\frac{\ln R / r}{2 \pi}=\text { is a constant }
$$

Since, the $\ln [\mathrm{R} / \mathrm{r}]$ varies slightly and it can be assumed that (UNESCO, 1984)

$$
\ln R / r \cong 7
$$

After converting the litre/minute to metre/sec equation 3 becomes:

$$
K(\mathrm{~m} / \mathrm{sec})=1.85 \times 10^{-5} \frac{Q / L}{\Delta H}
$$

According to Houlsby (1976) the Lugeon value is given as follows:

$$
\text { Lugeon value }(L V)=\frac{Q / L}{\Delta H} x 10 b a r
$$

If we express the pressure in meter instead of bar since 1 bar is equal to $10 \mathrm{~m}$ then the above formula can be rewritten as follows:

$$
\text { Lugeon value }(L V)=100 \frac{Q / L}{\Delta H}
$$

If we divided both sides by 100equation 8 becomes

$$
\frac{Q / L}{\Delta H}=\frac{L V}{100}
$$

Therefore, if we substitute equation 9 in equation 6 then, the $\mathrm{K}$ (hydraulic conductivity) value can be explained in Lugeon value that is:

$$
K[\mathrm{~m} / \mathrm{sec}]=1.85 \times 10^{-7}[L U]
$$

\section{METHODOLOGY}

The methodology used to arrive at the objective is correlation among the different methods based on the data taken.

\subsection{The Houlsby and Reoper Methods}

Houlsby (1976) has indicated that the formula to find the Lugeon units is:

$$
L u=(\text { Litre } / \text { meter } / \mathrm{min}) \times \frac{10 b a r}{t p(\text { bar })}
$$

Where, $\mathrm{Lu}$ is Lugeon value Litre/meter/min is the volume of water taken in given minute per unit meter, tp is the test pressure (bar). 
a.

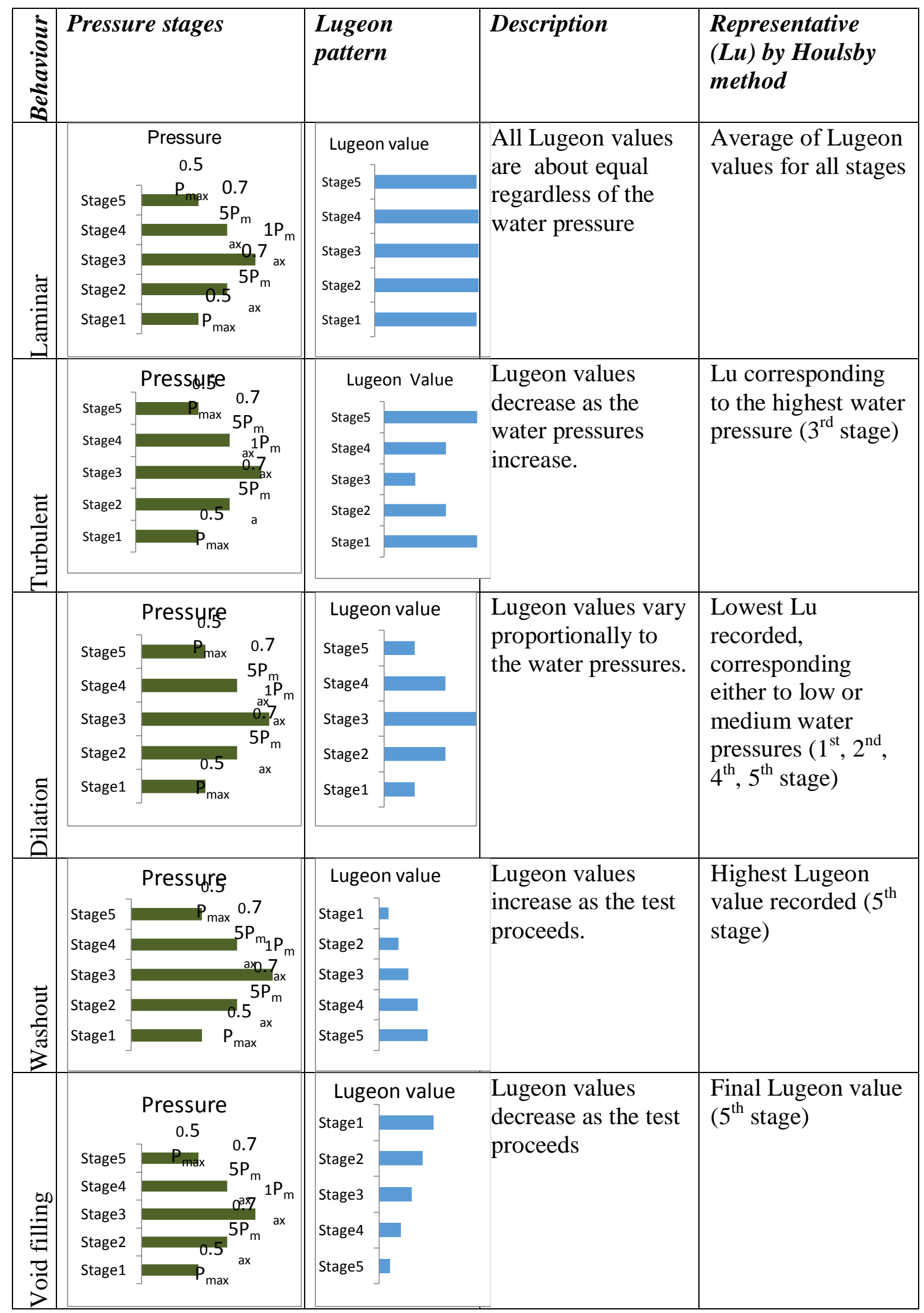


b.

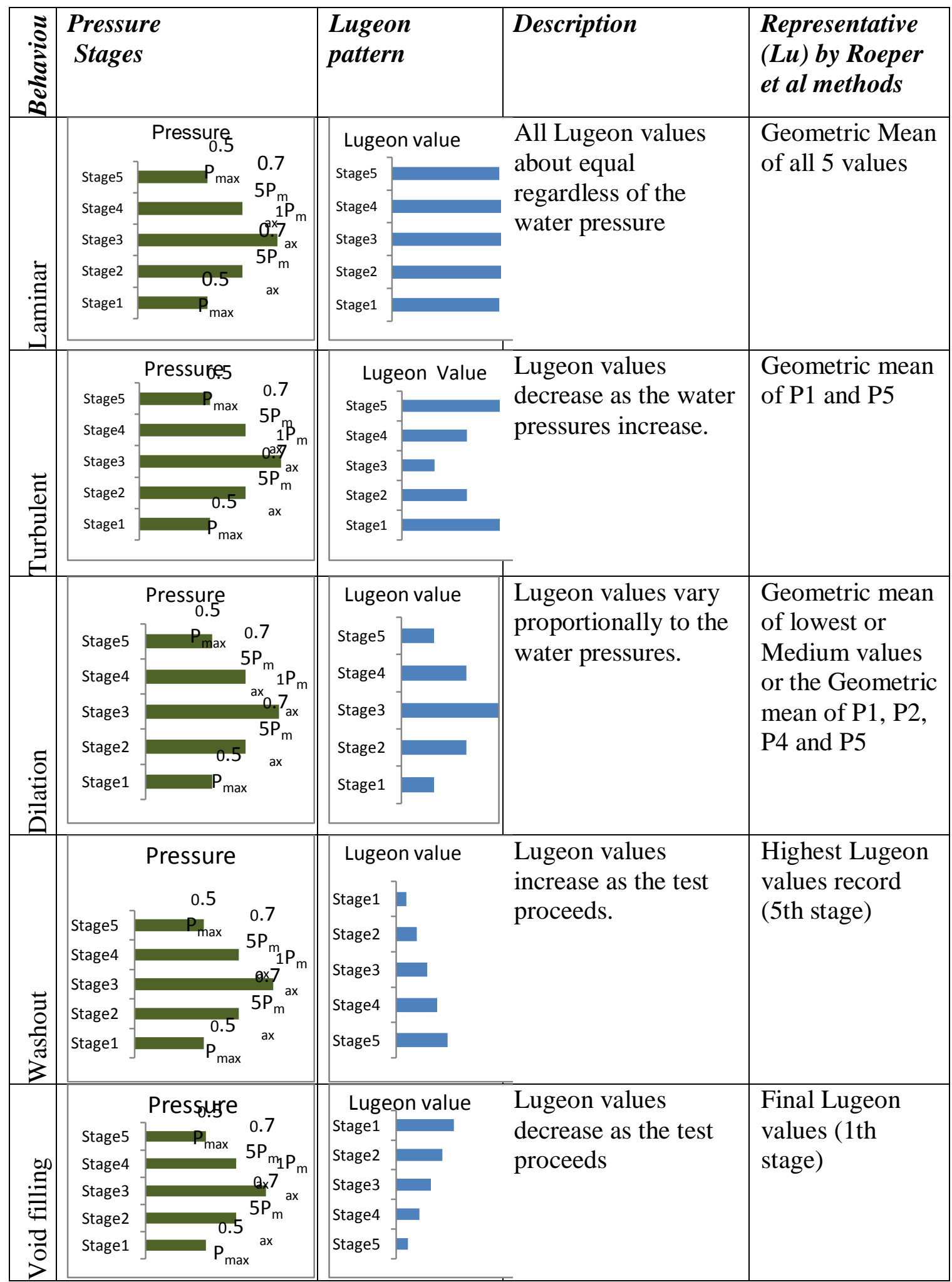

Figure 1. Summary of the current Lugeon interpretation practice proposed by a. Houlsby (1976); and b. Roeper et al. 1992).

The Houlsby method has modified the standard Lugeon by changing the constant pressure in to five pressures, which are designed in an increasing and decreasing fashion. 
Then, calculate the Lugeon unit for each of the pressure tests in the given test section. This method has also introduced the new way of interpretation by observing the calculated Lugeon values of the five pressure tests and selects the representative Lugeon unit for grouting purpose. The details of the patterns and the way of interpretation are explained in (Fig 1).

As discussed in the introduction part the Houlsby method was also modified by Reoper (1992) in the selection of the representative value based on the objective difference. That is, in the turbulent flow pattern, the selection of the minimum Lugeon value which cross-ponds with maximum pressure were proposed by Houlsby (1976). However, the Houlsby method was modified by Roeper et al. (1992) such that hydraulic conductivity is the geometric mean of the two lowest pressures results. Because it is assumed that the hydraulic conductivity calculated at this pressure is likely to be more reflective of the natural groundwater flow conditions. Moreover, in the void filling scenario, the Houlsby (1976) method proposes for the use of the final lower pressure value since this will likely be the representative condition of the rock during the pressure grouting process. Under natural flow conditions, however, these voids which are presumed to be the level of saturation will not be pressurized and thus the initial pressure value would be most representative.

As a common practice arithmetic mean, geometric mean and harmonic mean are also under use to select the representative value. In this paper a correlation analysis method will be carried out to find out if there is a significant difference between the different methods in use.

\subsection{Packer Test Data Collection Procedure}

A total of 75 packer tests conducted in seventeen boreholes were used in this evaluation (Taken from Mekelle Water supply Giba dam project). The test was conducted in limestone shale intercalation rock mass to find the hydraulic conductivity of a group of fractures. It was conducted using double packer test inflated by air and borehole diameter of $76 \mathrm{~mm}$. Water level measurements and height of manometer were reported. The time used to conduct test was at five minute interval that varies between 15 to 25 minutes in a single injection test. The total depth of each of the 17 boreholes varies from depth of 30.57 to $120.40 \mathrm{~m}$.

In general, the thickness of the test section is a function of the average spacing of the fissures and the extent of groundwater flow. According to UNESCO (1984), the thickness of the test section is specified to vary between 3-5 m. In this study the location and thickness of the test section are determined based on the core log data analysis and most of the test section is $3.5 \mathrm{~m}$ thick. According to Milanovic (1981) however, the use of fixed test section without 
understanding the location of the fracture can give unrealistic results because the result is cumulative.

Controlled injection pressure is used primarily to maintain the laminar groundwater flow around the test hole. A controlled injection pressure is important to avoid any change in natural geometry of fractures by water hammer that can result in the change of the hydraulic property. To avoid water hammer, it is suggested a step wise increase of the injection pressure (Houlsby, 1976; Milanovic, 1981; UNESCO, 1984). That is a three increasing and two decreasing injection pressures have been used. The injection pressure used varies with depth as recommended by Houlsby (1976). In this study for the minimum test depth (9.70$13.20 \mathrm{~m})$ zone 1, 1.5, 2.5, 1.5, 1 bar and for the maximum test depth (91.65-95.15 m) zone 3, 6, 10, 6, 3bar injection pressures were used. The general schematic diagram arrangement of the packer tests are shown in figure 2.

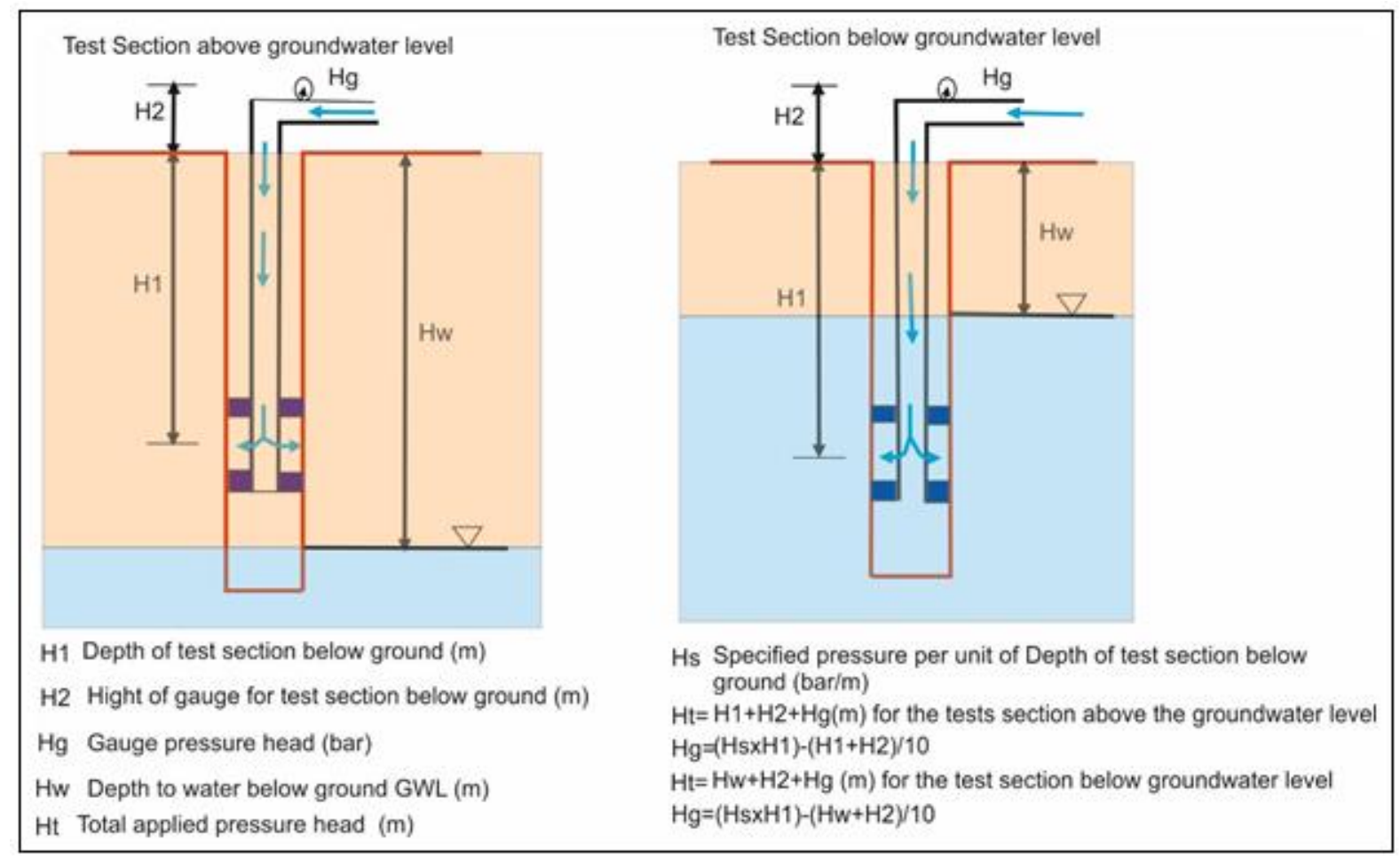

Figure 2. Schematic arrangement of packer test in case the test section is below and above groundwater after Klassen (1987), but modified for the units.

In the standard Lugeon method, there is no need of selecting the representative Lugeon value because only one test is conducted in a single test section. However, in the Houlsby method, it is indicated that in a single test section we conduct five tests, where the pressure is applied in an increasing and decreasing fashion. The question is out of the five Lugeon values obtained from a given test section which one of the Lugeon value represents 
the test section and how do we select the representative value from the five results. Houlsby (1976) has put the method of selection of representative Lugeon value for grouting purposes. On the other hand, Roeper et al. (1992) has put some modification on the Houlsby (1976) methods of selection for hydrogeological purposes.

\section{ANALYSIS AND DISCUSSION}

\subsection{The Packer Test Data Analysis}

The analysis of packer test data includes graphical analysis of the data obtained from the test area. This includes graphs of the flow rate $(\mathrm{Q})$ versus effective pressure $(\mathrm{P})$ and the graphs of the Lugeon value $(\mathrm{Lu})$ versus the applied pressure $\left(\mathrm{p}_{\mathrm{e}}\right)$.

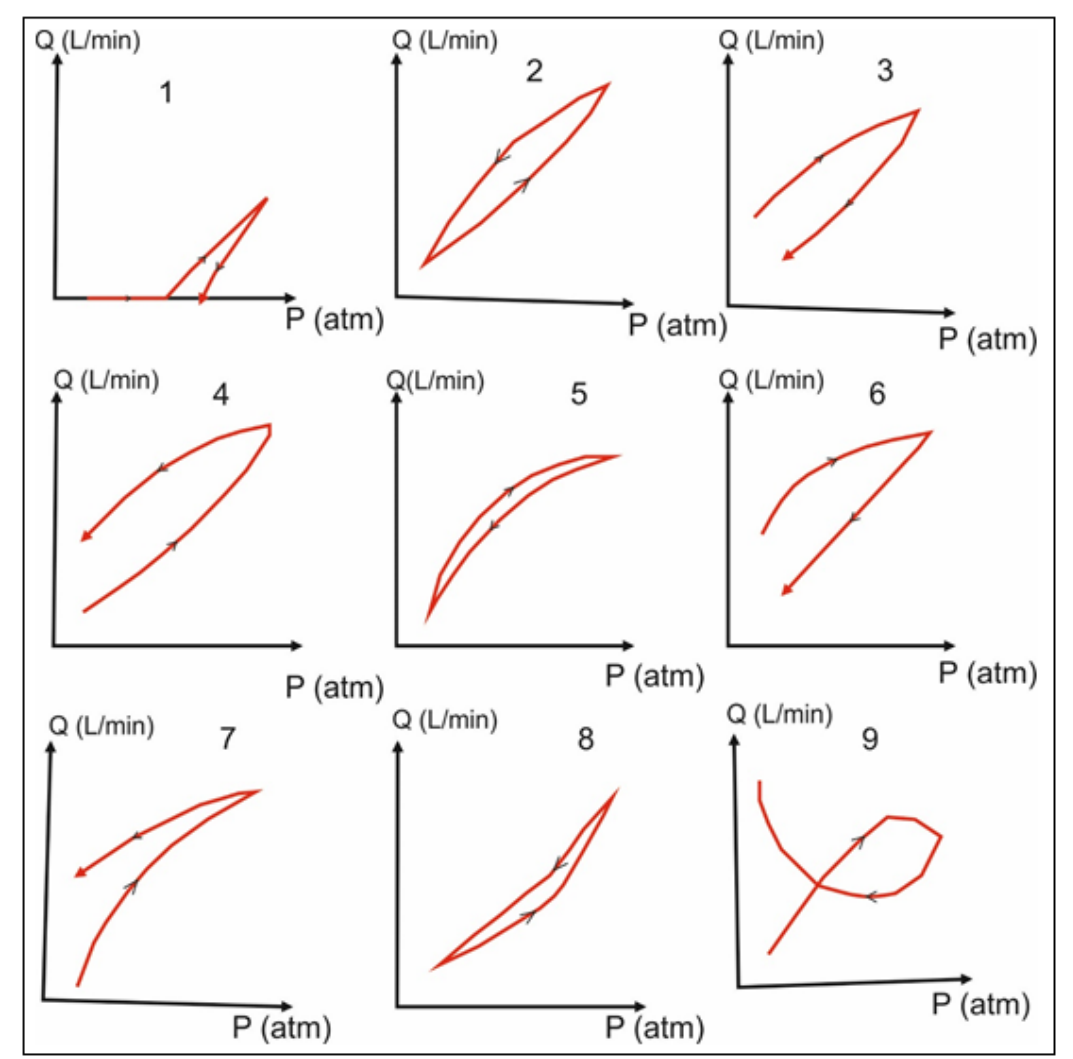

Figure 3. Most frequent diagrams determined by interpretation of permeability tests data obtained by Lugeon tests (Milanovic, 1981).

The analysis of the flow test result can be conducted by plotting the values of the injection water (Q) and the total pressure based on Milanovic (1981). The data is put in a graph with the $\mathrm{x}$-axis is the total pressure and the $\mathrm{y}$-axis is the flow rate. A correct test has to give a matching reversible cycle indicating no change in the void geometry. Any substantial disturbance as opening or clogging of the fractures is detected from the characteristics curve. According to Milanovic (1981), the Q-P graph reflects a specific type of porosity during the 
water flow under test pressure through a particular section of the fracture. According to Milanovic (1981) he has classified the type of the Q-P graph into nine and the graphs were related to the property of the tests section during the analysis and interpreted as described in figure 3 .

Therefore, the interpretation of each of the flow-pressure graphs in (Fig 3) is specified as follows Milanovic (1981): graph (1) indicates an impermeable media but with increased pressure some fractures are formed, graph (2) indicates a linear flow in relatively tight fractures in the test section, graph (3) a process of an eventual sedimentation in the fractures during the test, graph (4) shows a process of wash out from the test section, graph (5) indicates the presences of open fractures which result in the turbulent flow, graph (6) indicates non-linear relationship of flow and pressure similar to five by the hydrogeological conditions but different from it the cracks being deposited, graph (7) shows wash out effect, graph (8) shows the discharge increase for higher pressure and graph (9) anomalies that difficult to explain from hydrogeological point of view.

The analyzed data was treated based on the flow versus pressure graph interpretation method according to this method of analysis out of the 75 total data 19 of the test data result indicate impermeable media, 27 of the total data indicate linear flow, 3 of the data show sedimentation, 11 of the total data indicate washout, 4 of the total data indicate turbulent flow, 6 of the total data indicates discharge increase for higher pressure and 2 out of the tests indicate back pressure during the test. To see the characteristics of the Q-P graphs relationship based on the Milanovic (1981) method of analysis the graphs of core log well DA-BH-08 with 12 test section are given in figure 4. In this study the result of one core log data analysis result is put for comparison how much the data fits with the interpretation method given by the Houlsby graphs (Fig 5).

During the analysis, it is not only the flow rate $(\mathrm{Q})$ versus total pressure $(\mathrm{P})$ used but also the Houlsby (1976) graphic method which uses Lugeon value (Lu) versus applied injection pressure $\left(\mathrm{P}_{\mathrm{a}}\right)$ was also used to specify the hydrogeological property of the test section. According to Houlsby (1976), the patterns of the graphs were classified as laminar flow, turbulent, dilation, washout and void filling. For the pattern specification by Houlsby (1976) see the (Fig 1).

The analysis of the Lugeon value versus injected pressure graph reveal that 18 of the total data indicate laminar flow, 25 of the total data turbulent, 11 of the total data dialation , 9 and 3, of the total data, indicate washout and void filling respectively (Fig 6). About 7 of the 
test section indicate an impermeable nature of the rock and the remaining 2 tests sections show back pressure.

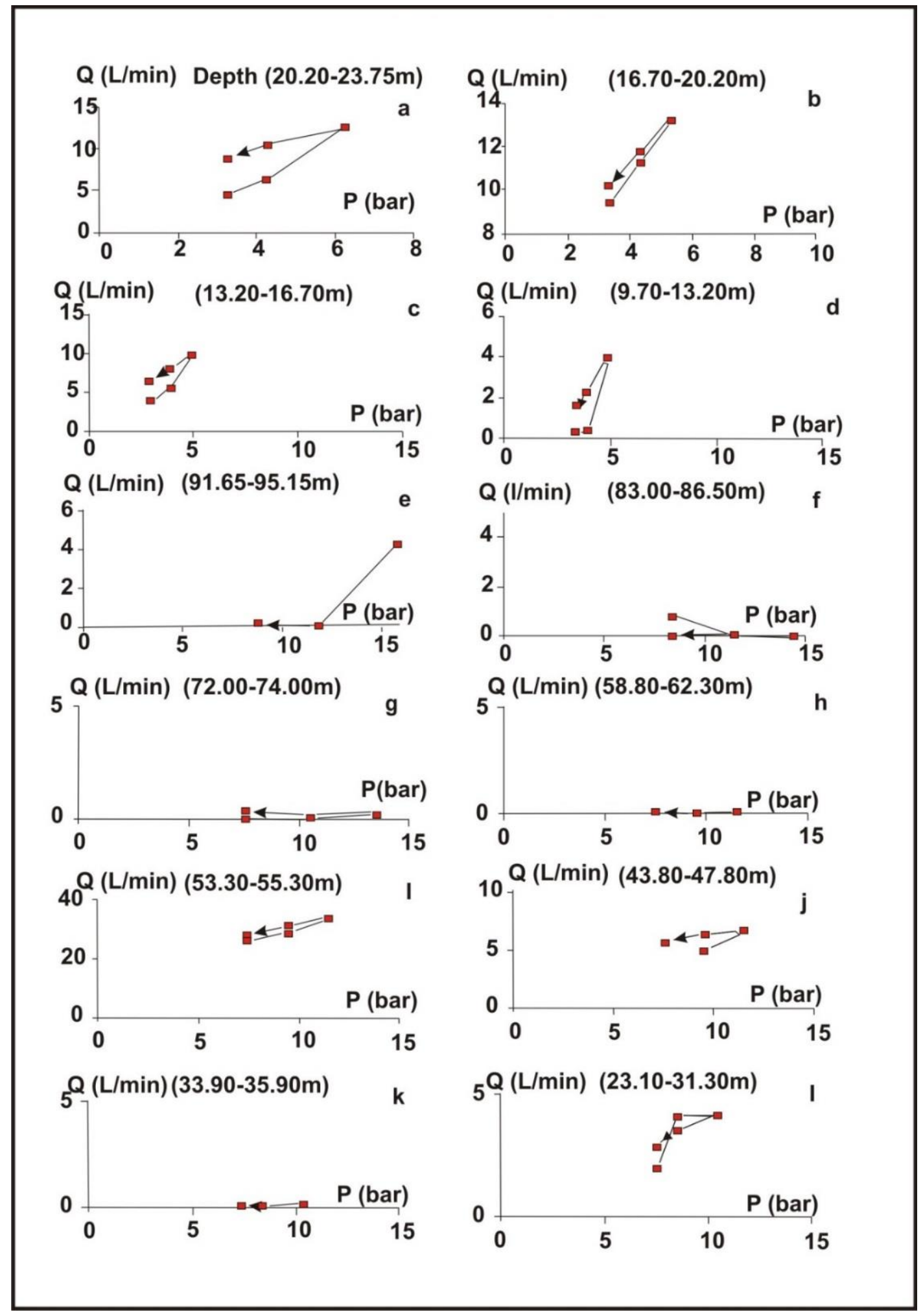

Figure 4. This shows the graph of the total pressure applied against flow rate value in each test section in core log DA-BH-08 in test sections 01-12. 


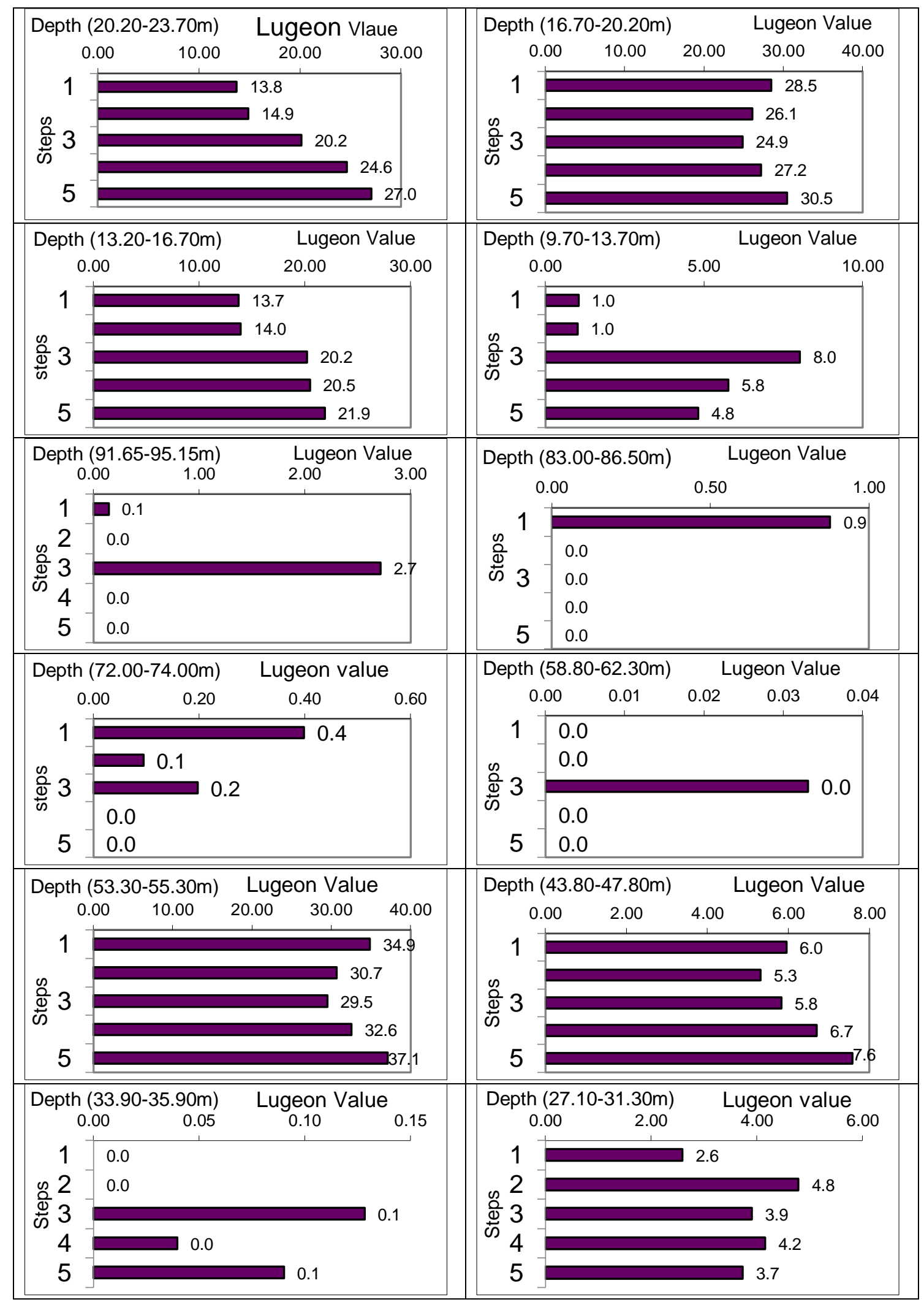

Figure 5. The Lugeon pattern graph for core log DH-BH-08-01 for 12 test sections. 


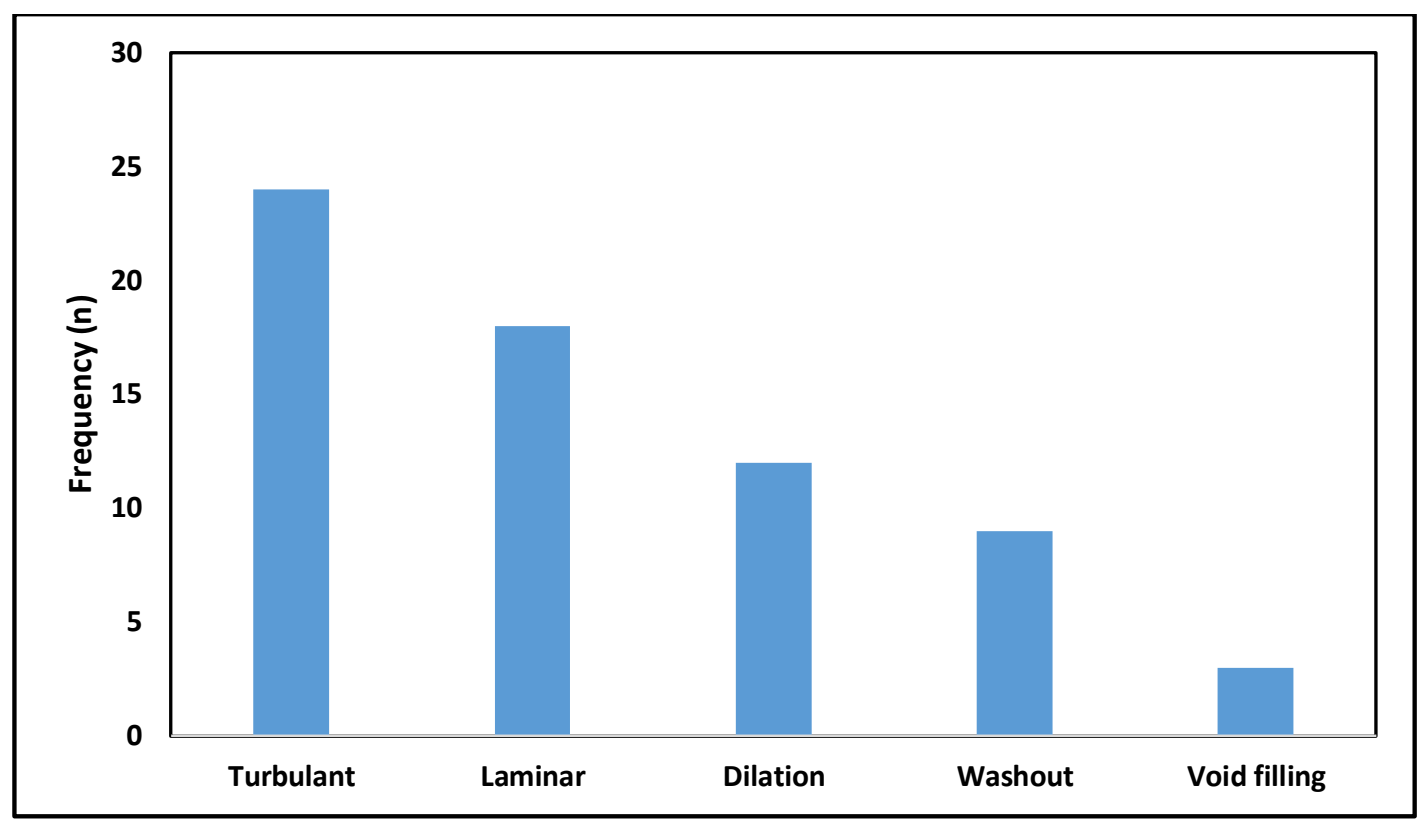

Figure 6. Frequency of patterns in the conducted packer tests.

Table 1. Interpretation of the results based on the Houlsby (1976) method.

\begin{tabular}{|c|c|c|c|c|c|c|c|}
\hline Well No. & Laminar & Turbulent & Dialation & Washout & $\begin{array}{l}\text { Void } \\
\text { filling }\end{array}$ & Impermeable & Total \\
\hline DA-BH-08-01 & 7 & 1 & 2 & 2 & & & 12 \\
\hline DA-BH-08-02 & 3 & & 2 & & & 2 & 2 \\
\hline DA-BH-08-03 & 1 & 6 & 3 & 1 & & 0 & 12 \\
\hline DA-BH-08-03 (sub) & & 1 & 1 & & & 1 & 3 \\
\hline DA-BH-08-06* & 2 & & 1 & & 1 & 4 & 8 \\
\hline TN-BH-08-07 & & 3 & & 2 & & & 5 \\
\hline DA-BH-08-08 & & & & & 1 & & 1 \\
\hline DA-BH-08-09 & & & & & 1 & & 1 \\
\hline DA-BH-08-10 & & 2 & & & & & 2 \\
\hline SP-BH-08-11 & 1 & & & 1 & & & 2 \\
\hline RE-BH-08-12 & 1 & 1 & & & & & 2 \\
\hline RE-BH-08-13 & & 1 & & & & 1 & 2 \\
\hline RE-BH-08-14 & & 2 & & & & & 2 \\
\hline DA-BH-08-16* & 3 & & & & & & 3 \\
\hline RE-BH-08-17 & & & & 2 & & & 2 \\
\hline DA-BH-08-18 & & 1 & & & & & 1 \\
\hline SB-BH-08-19 & & & & & & 1 & 1 \\
\hline DA-BH-08-20 & & 3 & & & & & 3 \\
\hline RE-BH-08-21* & & 3 & 3 & 1 & & & 7 \\
\hline
\end{tabular}

* Inclined wells. 
Table 2. Interpretation of results based on the flow-pressure method between the two methods of analysis used.

\begin{tabular}{|c|c|c|c|c|c|c|c|c|}
\hline Well code & Laminar & Turbulant & Dialation & Washout & $\begin{array}{l}\text { Void } \\
\text { filling }\end{array}$ & $\begin{array}{l}\text { Imper- } \\
\text { meable }\end{array}$ & All & Remark \\
\hline DA-BH-08-01 & 2 & & & 4 & & 5 & 11 & undefined \\
\hline DA-BH-08-02 & 1 & & & 1 & & 3 & 5 & Anomalies \\
\hline DA-BH-08-03 & 3 & & & 1 & & & 4 & \\
\hline DA-BH-08-03[sub] & & & & 2 & & 1 & 3 & \\
\hline DA-BH-08-06x & & 2 & & & & 5 & 7 & Annomaly \\
\hline TN-BH-08-07 & 3 & & & 1 & & & 4 & Annomaly \\
\hline DA-BH-08-08 & 1 & & & & & & 1 & \\
\hline DA-BH-08-09 & & & & & & & & Anomaly \\
\hline DA-BH-08-10 & 1 & & & 1 & & & 2 & \\
\hline SP-BH-08-11 & & & & 1 & & & 1 & Anomaly \\
\hline RE-BH-08-12 & 1 & & & & & & 1 & Anomaly \\
\hline RE-BH-08-13 & & & & & & & & $\begin{array}{l}\text { Sediment- } \\
\text { ation }\end{array}$ \\
\hline RE-BH-08-14 & 1 & 1 & & & & & 2 & \\
\hline DA-BH-08-16x & 2 & & 1 & & & & 3 & \\
\hline RE-BH-08-17 & & & 1 & & & & 1 & Anomaly \\
\hline DA-BH-08-18 & & & & & & & & Anomaly \\
\hline SB-BH-08-19 & & & & & & & & $\begin{array}{l}\text { Back } \\
\text { pressure }\end{array}$ \\
\hline DA-BH-08-20 & & & 1 & & & & 1 & Anomaly \\
\hline RE-BH-08-21x & 1 & 4 & & & & & 5 & Anomaly \\
\hline
\end{tabular}

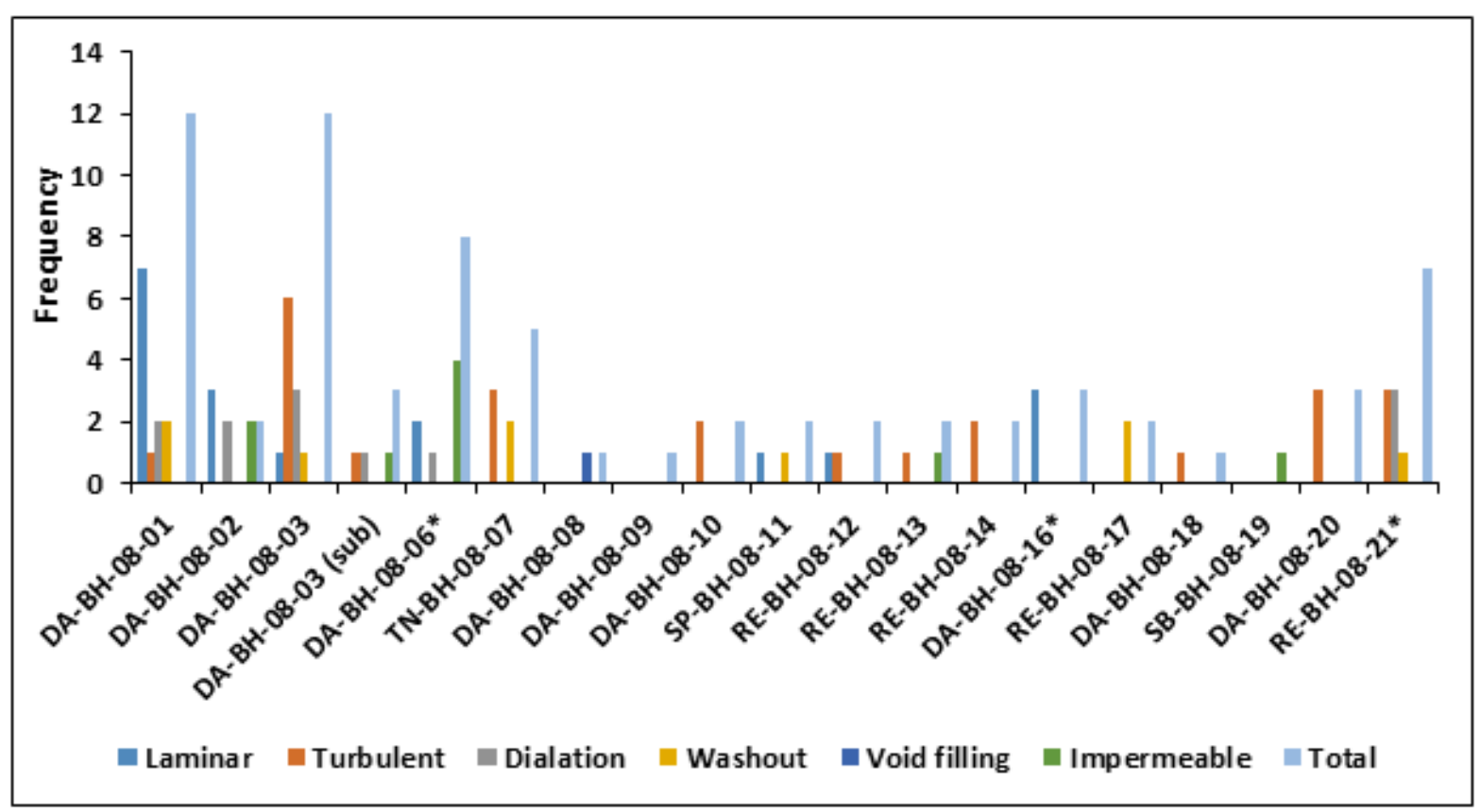

Figure 7. The Lugeon pattern based on the Houlsby (1976) method. 


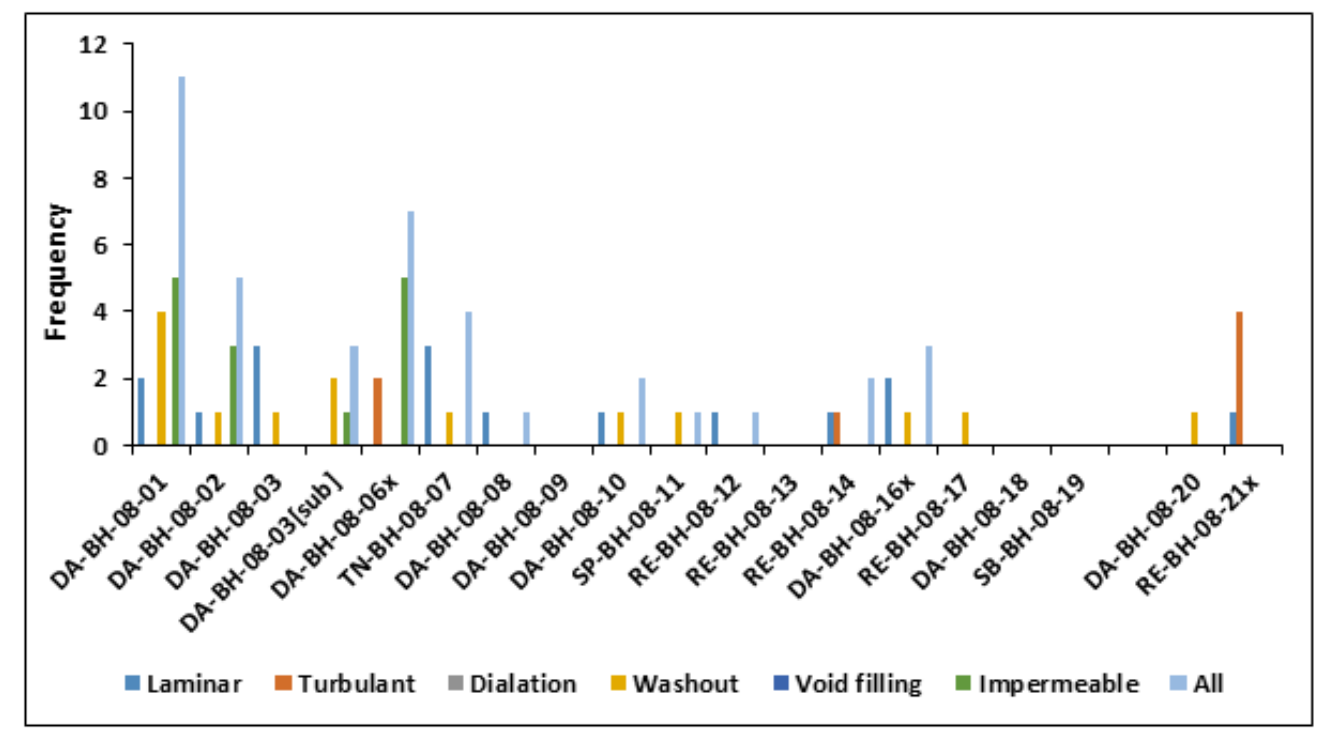

Figure 8. The Lugeon distribution pattern based on the flow rate vs pressure.

The analysis of the data was conducted using two methods Milanovic and the Housby method. But the first method which uses the flow-pressure has two problems. One problem is during the interpretation many graphs are available, which cannot be interpreted by the given type graphs. The second problem is many types graphs are not unique. Moreover, the comparison among the two methods indicates that there is mismatch i.e. for the same tests section there is different interpretation result. For comparison of the two methods the interpretation of the data is given in tables 1 and 2 and (Figures 7 and 8). For the reason mentioned above, only the Houlsby (1976) method will be used for the interpretation of the patterns and selection of the representative Lugeon value.

\subsection{Comparison of the Methods Used to Estimate a Lugeon Value}

The data from each test section were entered into a computer database, which includes well code and test number, depth, the calculated Lugeon value at each of the respective pressure the two minimum pressure, two medium pressure and the single peak pressure. The representative Lugeon values for each of the test section was calculated based on the mean methods and selected based on the Houlsby (1976); and Roeper et al. (1992) method. Then, the result of each of the method was put in a graph for correlation (Fig 9).

The Lugeon value for each of the test section was calculated using different methods; arithmetic mean, geometric mean, harmonic mean, Houlsby method and the Modified Lugeon analysis. The calculation result for each of the methods mentioned above the minimum and maximum value are given in table 3. 
Table 3. Maximum and minimum Lugeon for each method.

\begin{tabular}{|llllll|}
\hline & A.Mean & G.Mean & H.Mean & Houlsby & Modified Houlsby \\
\hline Minimum & 0 & 0.17 & 0.11 & 0 & 0.22 \\
\hline Maximum & 94.2 & 91.85 & 89.3 & 89.02 & 115.85 \\
\hline
\end{tabular}

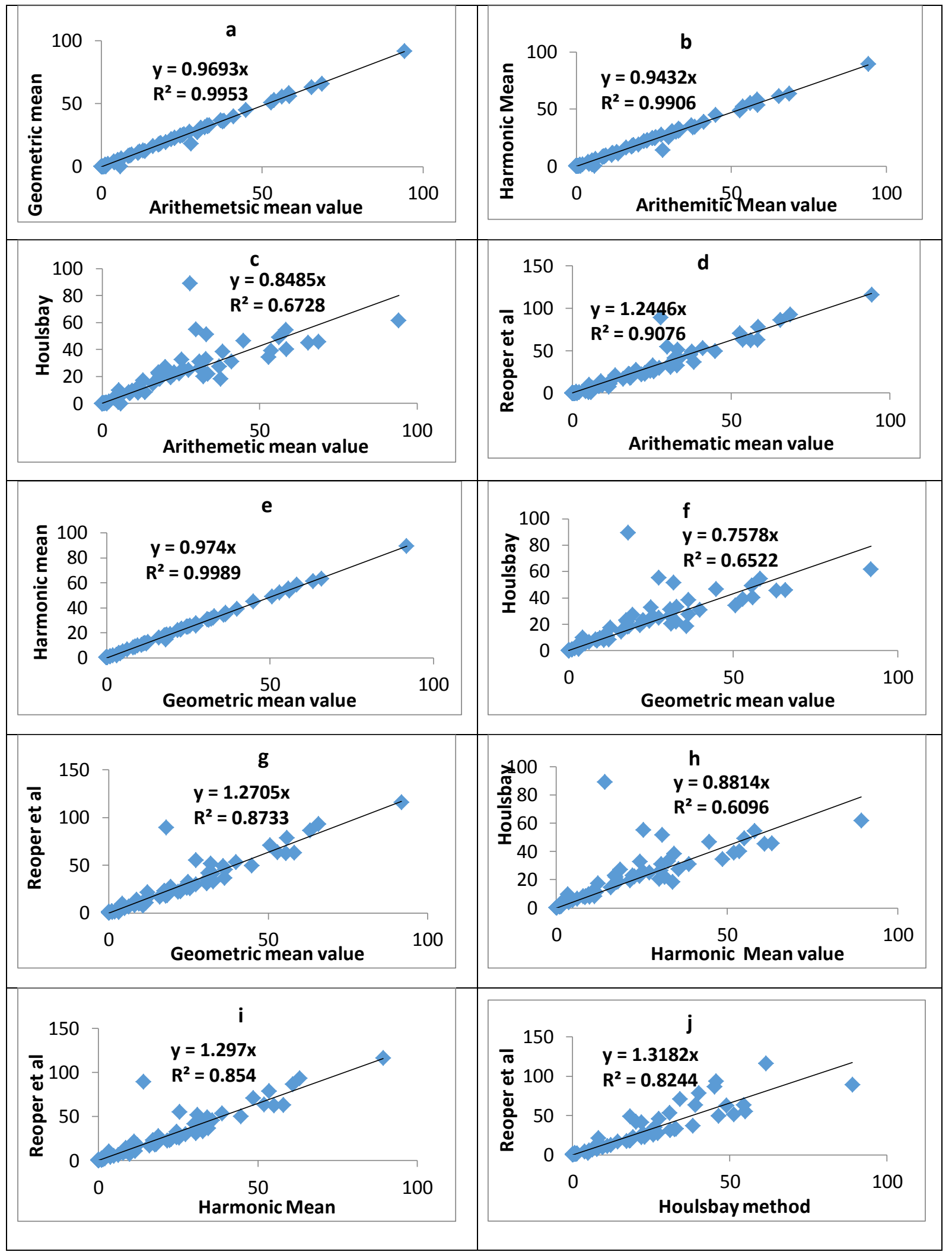

Figure 9. Correlation plot. 
After we put the Lugeon value of each method in a correlation graph the comparison was made using two important parameters. That is correlation coefficient value $\left(\mathrm{R}^{2}\right)$ and the slope of the equation of the correlation graph. Based on the idea that if the two methods are similar we expect the Lugeon result from the two methods to have comparable result for a given test section. Based on this ideal we expect to have a graph with a slope of one.

From the graph we can note that there is very good correlation value among the different means (arithmetic, geometric and harmonic) with correlation coefficient value and a slope values between 0.991-0.999 and 0.943-0.974 respectively. This indicates no significant variation among the different mean. The other comparison was made among the different means and the Houlsby method the correlation coefficient varies between 0.610-0. 673 and the slope of the graph varies between 0.758-849. This reveals significant difference as compare to the variation among the means. The other comparison made between Reoper method and different means has indicated a correlation coefficient variation between 0.854 0.908 and a slope that varies between 1.24-1.3. Finally, we have compared the Lugeon value derived from Houlsby and Roeper et al. (1992) methods the result correlation reveals that there is a correlation coefficient value of 0.824 and slope value of 1.32 .

Analysis made between the different methods indicates that the arithmetic mean shows good correlation with Roeper et al. (1992) method than with Houlsby (1976) method with a correlation value of 0.91 but the slope is 1.25 i.e. if the arithmetic mean value has one then the Reoper et al. (1992) method analysis for hydrogeological investigation is about 1.25

\section{CONCLUSION AND RECOMMENDATION}

Based on the result we conclude that for grouting purposes it is good to obey the Houlsby method than using the different means as they have relatively poor correlation and show over exaggeration of the value. For hydrogeological purposes, it is possible to use the different means in general the arithmetic mean in particular as there is good correlation. However, care should be given as there is small underestimation of the value when we use the different means as compared with the Reoper method. Finally, a further study in different type of rocks and in different places is recommended to further strengthen this study.

\section{ACKNOWLEDGEMENTS}

Authors duly acknowledge Water Resource Bureau of Tigray region, Ethiopia for allowing to use raw packer data and the anonymous reviewers for providing critical comments. 


\section{REFERENCE}

Gale, J. E. 1982. Assessing the permeability characteristics of fractured rocks. In: T.N. Narasimhan (ed.), Recent Trends in Hydrogeology, Geologocal Society of America Special paper, 163-81 (DOI: https://doi.org/10.1130/SPE189-p163).

Houlsby, A.C.1976. Routine Interpretation of the Lugeon Water-Test. Quarterly Journal of Engineering Geology, 9:303-313.

Houlsby, A. C. 1990. Construction and Design of Cement Grouting: A guide to grouting in Rock Foundations. Volume 67 of Wiley Series of Practical Construction Guides, ISSN 0271-6011, John Wiley \& Sons, Inc., 442p.

Klassen, V. R. 1987. Packer Test, A report submitted to J. A. Gillies in partial fulfilment of the requirement of AE825.3, Agricultural Groundwater Hydrology, University of Saskatchewan, Saskatoon, Saskatchewan.

Lugeon, M. 1933. Barrage et G'eologie. Dunod. Paris

Milanovic, P.T. 1981. Karst Hydrogeology. ISBN-10: 0918334365; ISBN-13: 9780918334367, Water Resources Publications, Littleton, 434p.

National Research council (NRC). 1996. Rock Fractures and Fluid Flow: contemporary Understanding and Applications. National Academy press, Washington DC. 551p.

Novakowski, K.S \& Bickerton, G.S.1997. Measurement of the Hydraulic properties of lowPermeability rock in boreholes. Water Resources, 33(11): 2509-2517.

Quinones-Rozo, C. 2010. Lugeon Test Interpretation, Revisited. Abstract, $30^{\text {th }}$ Annual Conference volume, "Collaborative Management of Integrated Watersheds", US Society of Dams, 405-414.

Roeper, T.R., Soukup, W. G \& O’Neill, R. L. 1992. The Applicability of the Lugeon Methods of Packer Test Analysis to Hydrogeologic Investigation. Focus Conference on Eastern Regional Groundwater Issue, National Groundwater Association, Dublin, 8(3):29-36.

Thiem, G. 1906. Hydrologische methoden, Leipzig: Gebhardt, 56p.

United Nations Educational, Scientific and Cultural Organization (UNESCO) 1984. Guide to the hydrology of carbonate rocks, place de Fonteny, 75700 Paris, France, 345.

Wenzel, L.K. 1936. The thiem method for determining the permeability of water-bearing materials and its application to the determination of specific yield, results of investigations in the platte river valley, Nebr: U.S.G.S.Water-supply paper,679-A:157. 